\title{
Aphantasia, imagination and dreaming
}

\author{
Cecily M. K. Whiteley ${ }^{1}$
}

Accepted: 28 August 2020/Published online: 18 September 2020

(C) The Author(s) 2020

\begin{abstract}
Aphantasia is a recently discovered disorder characterised by the total incapacity to generate visual forms of mental imagery. This paper proposes that aphantasia raises important theoretical concerns for the ongoing debate in the philosophy and science of consciousness over the nature of dreams. Recent studies of aphantasia and its neurobehavioral correlates reveal that the majority of aphantasics, whilst unable to produce visual imagery while awake, nevertheless retain the capacity to experience rich visual dreams. This finding constitutes a novel explanandum for theories of dreaming. Specifically, I argue that the recent dream reports of aphantasics constitute an empirical challenge to the emerging family of views which claim that dreams are essentially imaginative experiences, constitutively involving the kinds of mental imagery which aphantasics, ex-hypothesi, lack. After presenting this challenge in the context of Jonathan Ichikawa's recent arguments for this view, I argue that this empirical challenge may be overcome if the imagination theorist abandons Ichikawa's account of dreaming in favour of a modified version. This involves the claim that dreams are essentially inactive and constitutively involve non voluntary forms of imagination. I conclude with a suggestion for further research which can test the viability of this alternative hypothesis, and move the debate forward.
\end{abstract}

Keywords Aphantasia - Imagination · Dreaming · Imagination model of dreaming

Cecily M. K. Whiteley

c.whiteley@1se.ac.uk

1 Department of Philosophy, Logic, and Scientific Method, London School of Economics,

Lakatos Building, Portugal Street, Holborn, London, UK 


\section{What are dreams?}

An emerging debate in the philosophy and science of consciousness concerns the nature and ontological status of dreams. Much discussion has focused on solving what Jennifer Windt (2015) calls the 'conceptualisation problem': how, if at all, ought we to account for dreaming using the standard psychological terms (such as perception, hallucination, thought and emotion) used to characterise wakeful consciousness? According to one growing family of views, dreams are best understood in ontic terms as instances of imaginative experiences. The so-called 'imagination model of dreaming' has been influentially developed by Jonathan Ichikawa (2009, 2016), who argues that dreams constitutively involve both sensory and propositional forms of imagination. In addition to conceptual lines of argument, Ichikawa maintains that the imagination model of dreaming receives considerable support from various forms of neuropsychological evidence which suggest dream imagery and waking imagery share a common neural basis (Solms 1997; Foulkes 1999).

Here, I present an empirical case against the imagination model of dreaming as presented by Ichikawa $(2009,2016)$. I analyse a series of recent neurological studies which identify a particularly pure case of imagery generation disorder known as aphantasia (Zeman et al. 2015, 2016). Subjects with aphantasia-'aphantasics'are characterised not just as having mental imagery of a reduced vividness, or the incapacity to produce imagery of certain visual kinds, but as lacking the capacity or power to produce visual forms of mental imagery altogether. Whilst the recent findings on aphantasia have previously been considered in relation to the ongoing 'imagery debate' in cognitive science which concerns the nature of mental imagery and its cognitive function (Zeman et al. 2015; Kosslyn et al. 2006), the full theoretical significance of aphantasia and its implications for debates about the nature of dreaming have yet to be considered. Bolstered by the fact that these preliminary studies of aphantasia reveal that the condition can be both acquired (Zeman et al. 2010) as well as a lifelong stable condition (Zeman et al. 2015, 2016), this paper starts from the claim that subjects with aphantasia and their dream reports provide an interesting test case for philosophers and psychologists who posit a tight ontological connection between dream mentation and sensory forms of imagination.

The plan for the paper is as follows. Sections 2 and 3 outline Ichikawa's imagination model of dreaming $(2009,2016)$ and the empirical case offered in support of it. Section 4 introduces the recent studies on aphantasia and the notable neurobehavioural features of the condition that these highlight. In Sect. 5 I bring these together and argue that the dream reports of aphantasic subjects recorded to date present an empirical challenge to the imagination model of dreaming presented by Ichikawa. My argument, which results in a dilemma for Ichikawa, is based on the following claims: (i) Ichikawa is committed to the claim that dreams often involve visual forms of mental imagery - which he characterises as essentially agential phenomena-as central and constitutive components, (ii) that aphantasic subjects ex hypothesi lack the capacity for these kinds of agential experiences and (iii), that aphantasic subjects nevertheless report having rich visual dreams. Insofar 
as this goes against the predictions made by the imagination model, I argue that these studies thus appear to disconfirm Ichikawa's theory, and in doing so, problematically lend support to alternative accounts which the imagination model was meant to replace. In Sect. 6 I consider a way in which the proponent of the imagination model can respond to this empirical challenge. The aphantasia studies notably suggest a strong neurophysiological dissociation between voluntary and involuntary forms of mental imagery, with only the capacity for the former being lost by the majority of aphantasic subjects. I argue that the strongest response available to the imagination theorist is to take up the recent calls for adoption of a variation of the imagination model according to which non-lucid dreams essentially involve involuntary, passive or inactive forms of imagination (O'Shaughnessy 2002; Soteriou 2017; Crowther 2018). I conclude in Sect. 7 with a discussion of the broader implications of aphantasia for theories of dreaming. This includes a proposal for future dream research which can shed light on the empirical viability of this alternative model of dreaming, and move contemporary debate on the conceptualisation question forward.

\section{The imagination model of dreaming}

The claim that dreams in some sense involve imaginative experiences leaves open a number of more sophisticated ontological analyses of dreaming. ${ }^{1}$ Motivated by the rejection of the orthodox alternative to the imagination view, which claims that dreams are essentially hallucinations which involve misleading, wake-like sensory experiences (or 'percepts') leading to false beliefs, Ichikawa's formulation of the imagination model of dreaming involves a commitment to two central claims ${ }^{2}$ :

(i) Imagery: dreams essentially involve mental imagery-experiences of the kind which occur when we imagine what something looks, feels, smells or tastes like. 'Imagery' implies, for example, that when I dream of the white cliffs of Dover, my experience is of the same kind as that which I have when I close my eyes and imagine them in front of me when awake (and not, contra the hallucination account, the same kind of experience I would have if I were to visually perceive them). (2009, p.105).

\footnotetext{
1 Variations on this claim can be found, for example, in Sartre (1940), Walton (1990), O'Shaughnessy (2002) McGinn (2004), Sosa (2005, 2007, 2009), Ichikawa (2009, 2016), Thompson and Batchelor (2014), Soteriou (2013, 2017), Crowther (2018). The assumptions that dreams (a) are phenomenally conscious experiences that occur during sleep and (b) that these are reported accurately upon waking have not gone unquestioned-Malcolm (1956), Dennett (1976), Rosen (2013)—-however they are now widely accepted, and I do not press them here. A recent defense of these claims can be found in Windt and Metzinger (2007) and Windt (2015)).

${ }^{2}$ Versions of the hallucination model can be found in Descartes (1984), Hobson et al. (2003) and Revonsuo (2005). Alternatives to hallucination and imagination accounts include the view that dreams involve neither perceptual or imaginative experiences but are sui-generis immersive spatio-temporal hallucinations (Windt 2010, 2015), and the pluralist thesis that dreams essentially involve multiple different kinds of experience (Rosen 2012, 2019).
} 
And

(ii) Imaginings: the belief like states that we take towards the content of our dreams (whilst dreaming) are instances of propositional imagination. 'Imaginings' implies that when I dream that I am swimming the English Channel, I imagine that I am doing so; my dream does not involve my having the belief that I am in fact swimming the English Channel $(2009,111){ }^{3}$

The viability of this now-standard contrast between the hallucination and imagination models of dreaming depends on the acceptance of a number of substantive philosophical assumptions about the nature of imagination, perception and hallucination and the relations between them. Primarily, the presentation of the hallucination and imagination models as mutually exclusive theories depends on the presupposition that there is a difference in kind between imaginative phenomena on the one hand and perceptual-hallucinatory experiences on the other. That is, it requires acceptance of the view that there is a phenomenally determinable or otherwise essential difference between the categories of imaginative and perceptualhallucinatory experiences, such that the two are considered distinct kinds of mental phenomena. The rationale for this is as follows: if imaginative and perceptualhallucinatory experiences differ not in kind but in degree, as argued by Hume, then plausibly there ceases to be a substantive disagreement between proponents of imagination and hallucination theories of dreaming. ${ }^{4}$ Acceptance of this claim gives rise to a second, crucial, observation: any theory which seeks to provide an analysis of dreaming in terms of imagination needs to supplement this claim with a philosophical account of what imagination is. That is, if it is to be properly informative, an imagination model of dreaming ought to include within it an account of what it is to be an imaginative experience, as opposed to a perceptual or hallucinatory one. In addition to securing its status as a distinct mental kind from perception and other cognitive phenomena, this must also have the resources to accommodate the various commonalities and differences thought to hold between the two. ${ }^{5}$ Ichikawa thus combines his endorsement of imagery and imaginings with a further claim which serves as the final tenet of his theory:

(iii) Subject to the will: The crucial distinction between imagery and percepts is to be made on the basis that the former is necessarily "subject to the will".

\footnotetext{
3 See Sinhababu (2016) for a discussion of how so-called propositional or attitudinal imagination, as a distinct cognitive attitude, can be distinguished from belief.

4 Rosen (2019) includes a recent endorsement of this view. It is worth noting here that the vindication of this set up not only requires that imaginative and perception differ in kind (Kriegel 2015), but also that perceptual and hallucinatory experiences do not. That is, the dialectic here is further complicated by certain disjunctivist theories of perception, which deny that veridical and hallucinatory experiences are of the same fundamental kind (Martin 2004, 2006). This is particularly pertinent in light of the recent attempt to provide a positive disjunctivist analysis of hallucination in terms of sensory forms of imagination (Allen 2015). Again, on this view, hallucination and imagination models of dreaming would amount to the same thesis.

5 See Nanay (2016) for the difficulties associated with this task.
} 
That is to say, imagination is fundamentally an agentive phenomenon (2009, p. 106).

As a type of agentive theory, Ichikawa relies here upon the intuitive idea that the generation or production of mental imagery, as opposed to perception, essentially constitutes a mental act over which we have direct control. That is to say, the inception and content of our visual imagery is typically determined by us; experimental subjects can choose to visualise an apple as opposed to other pieces of fruit, for example, when asked to "imagine a piece of fruit" or an "inanimate object" in the lab. This is thought to contrast with the traditionally passive nature of veridical or hallucinatory perception, over which we exercise little control. While the agential nature of imaginings is well recognised, agentive theories claim not only that the agential origin of imaginings is common to the majority of imaginative episodes, but is rather constitutive of them. That is, that each and every imaginative experience is such that it is necessarily subject to the agent's will (2009; McGinn 2004). ${ }^{6}$

Does this commit Ichikawa to the implausible view that our dreams are under our control, and relatedly, that there can be no instances of so-called 'passive imaginings' - unbidden mental images, or earworms? Whilst other agentive theories of imagination, which differ in subtle ways from Ichikawa's account, are clear in their commitment to this latter claim - and thus are directly opposed to an analysis of dreaming in terms of imagination-Ichikawa doesn't think so. ${ }^{7}$ This is due to the fact that Ichikawa claims there is a distinction to be made between an experience having an agential origin or being 'subject to the will', and that same experience being under an agent's voluntary control. That is, he claims, following Wittgenstein (1967):

it is possible for something to be subject to the will, and yet not 'under voluntary control' - the annoying song that runs through your head is an example of something like this. It is subject to the will because it makes sense to try to banish it; it is not under your voluntary control because you are unable to succeed. We do not always voluntarily control the things we do; this does not stop them from being things we do (2009, p. 116, italics added). and,

Unwelcome imagery is more like an unwelcome habit or addiction than an unwelcome set of chains....even when our imagery is unwelcome and we cannot banish it, we can try to banish it; we know what it is to banish it. We are failing to perform an act. (2009, p. 107).

\footnotetext{
6 This agentialst characterisation is forcefully captured in Ichikawa's assertion that "to imagine is to act-our imagery is an important sense under our voluntary control; this is not so with percepts" (108). Ichikawa is thus rejecting epistemological and dependency theories of imagination (O'Shaughnessy 2000; Peacocke 1985; Martin 2001) which I return to briefly in Sect. 7.

7 See, for example, Dorsch (2012, 2015).
} 
This distinction between mental agency and voluntary control which Ichikawa appeals to here, and the criterion which he claims is sufficient to demarcate involuntary dream imagery from perceptual experiences, are somewhat vague and deserve further scrutiny and elaboration. For now, it is necessary only to state the notable implication of Ichikawa's model of dreaming, if this can be provided: that dreams and dream imagery, like involuntary imaginings, are essentially agential experiences over which we lack voluntary control; that is, whose content we can attempt — and fail -to banish. To use Ichikawa's terminology, dreams on this view are like pervasive unwelcome habits or addictive episodes which we, qua agents, do whilst asleep. They are, in virtue of being imaginative experiences, mental acts.

In virtue of endorsing these three claims, an imagination model of dreaming is thought to have direct implications for contemporary debates in the philosophy of mind, psychology and epistemology. Thus far, the imagination model has been discussed primarily within the context of (ii) imaginings, and its epistemological consequences in relation to Cartesian dream skepticism. ${ }^{8}$ However, recent discussion has concerned the potential of the imagination model of dreaming as an available contrast case to illuminate and motivate an analysis of the metaphysical constitution and epistemic function of wakeful consciousness, as a crucial, relatively neglected topic in the philosophy of mind (O'Shaughnessy 2002, 2008; Soteriou 2017; Crowther 2018). This, along with the potential of the imagination model to serve as a guide to empirical research in the science of dreaming (providing the much-needed conceptual clarification of the target phenomenon of this research) offers a strong mandate for discussion into the viability of the imagination model that Ichikawa presents and the success of the arguments offered in support of it.

\section{The empirical evidence for an imagination model}

\subsection{Dream development in children}

Whilst there is much to be said about the case for the second of Ichikawa's central claims - that dreaming involves taking an imaginative attitude towards the content of our dreams - and whether the imagination model of dreaming ought to commit to this claim, my focus here is on the arguments Ichikawa puts forward for (i) imagery, and in particular, the empirical evidence from cognitive and behavioural psychology he presents in favour of this thesis. Adopting an empirically-informed approach, Ichikawa presents two psychological considerations in favour of 'imagery' (2009, pp. 9-11; 2016, pp. 154-155,). The first concerns a series of long-term studies led by David Foulkes on dream development in children in the 1960s to the 1980s. In the first extensive longitudinal study of dreams (1982)-later documented and

\footnotetext{
8 Indeed, this is the primary motivation for Ichikawa's (2009, 104, 2016; pp. 157-158) and Sosa's (2005) presentations of the view. Here, the initial proposal is that taking an imaginative, as opposed to doxastic, attitude towards the content of our dreams provides the proponent of the imagination model with a compelling response to dream skepticism. For a more extensive discussion of the prospects for dream skepticism in this context however see Soteriou (2017) and Ichikawa (2008).
} 
analysed in his influential book 'Children's Dreaming and the Development of Consciousness' (1999)—Foulkes and his team analysed dream report data collected over 5 years from children aged 3-15 in conjunction with performing a variety of cognitive and personality tests. Their findings, based on reports systematically collected in the lab and at home over a 5 year period, were radical. In addition to consistently supporting the claim that young children and infants lack the capacity to dream-the leading scientific and folk hypothesis at the time-the results indicated that dreaming is a high level cognitive process which develops discretely over time in accordance with a number of identifiable stages. In addition to tracking changes in the frequency of dreams reported, these stages also mark discrete differences in dream content throughout childhood development which correspond to the type and quality of dream imagery, narration and active self representation. ${ }^{9}$ Here, Ichikawa cites the following observation from Foulkes' in support of the imagination model:

From all my data, the suggestion is that dreaming best reflects the development of a specific cognitive competence, indexed by certain kinds of tests of visual-spatial imagination, leading to the conclusion that imagination must be a critical skill in dream-making (1999, p. 90 italics added). ${ }^{10}$

That is, that children's visuospatial skills — which he and his team tested via tasks typically thought to require visual imagery and spatial imagination-was the only waking cognitive variable which correlated with, and developed alongside, high dream frequency and richness across the study.

\subsection{The neuropsychology of dreams}

The second set of studies Ichikawa presents in favour of imagery moves to cement this neuropsychological connection between dreaming and imaginative abilities in children to adults. Here, Ichikawa draws heavily on the work of neuroscientist Mark Solms, whose systematic review of the empirical literature on dream abnormalities - the first of its kind - and subsequent clinico-anatomical study of dreams, is presented in 'The Neuropsychology of Dreams' (1997). Investigating dreaming under neuropathological conditions, Solms aimed to identify changes in dreaming systematically associated with focal cerebral pathology and to describe their clinical and anatomical characteristics. In conjunction with his study of 361 neurological patients, Solms identifies four broad categories of dream abnormalities: those in which patients report (a) a global cessation of dreaming (b) the cessation or

\footnotetext{
9 These were later confirmed in Foulkes' cross-sectional study (1999, p. 116).

${ }^{10}$ Dream frequency and rich dream content did not correlate for example with increased verbal or memory skills, which seems to repudiate the alternative hypothesis available viz. that dreams in younger children and infants were occurring frequently yet were forgotten or not reported due to poor linguistic or recall abilities. See Foulkes (1999, 1996), and, for a nice discussion of the methodological issues raised here, Sutton (2009, pp. 532-536) and Rosen (2019, p. 2.2.5).
} 
reduction of visual imagery in dreams (c) increased frequency or vividness of dreams (dream-reality confusion) and (d) recurring nightmares.

According to Ichikawa, Solms' research provides empirical support for the imagination model of dreaming. This is based on the following finding on the behavioural correlates of (b): in cases in which a cessation in visual dream imagery was reported, the same patients reported a further cessation of waking visual imagery or, in cases in which dream imagery was reduced as opposed to absent, that their waking imagery was analogously deficient $(74,93-102,228) .{ }^{11}$ Ichikawa maintains that such cases provide a useful means of testing the empirical credibility of the account of dreaming he defends: "Considering patients with brain damage resulting in imaginative deficits is particularly illuminating: such subjects tend to exhibit precisely analogous deficits in dreaming" (2016, p. 254). Insofar as this study and similar work (Solms and Turnbull 2002) appear to support a structural connection between dreaming and imagination, Ichikawa concludes that these, in conjunction with the conceptual arguments he presents (2009, pp. 108-109), provide a compelling case in support of imagery, and by extension, his imagination model of dreaming.

There is more to be said about these two empirical considerations and their relation to Ichikawa's central thesis. For my purposes, the important feature of Ichikawa's discussion here is the methodological commitment it highlights. In drawing on these psychological considerations to support his imagination model of dreaming in the manner just described, Ichikawa commits himself to the claim that neuropsychological findings about the neural basis of dreaming and mental imagery serve as important test cases for philosophical accounts of dreams. That is, a natural redescription of Ichikawa's reasoning here is as follows: support and accommodation of empirical cases like these-specifically, cases in which waking imaginative capacities are reduced or impaired - is an important desideratum on an adequate philosophical theory of dreams. ${ }^{12}$ The aim in the following sections is not to argue against this claim-it is widely accepted-but rather to argue that this methodological commitment, in the context of a new imagery generation disorder, provides reason to reject one of Ichikawa's central claims, and thus turn Ichikawa's psychological case on its head.

\section{Aphantasia and dreaming}

The psychological case serving as the focus of this paper is the contemporary rediscovery of a particularly pure case of imagery generation disorder known as 'aphantasia' (Zeman et al. 2010, 2015, 2016, 2018). ${ }^{13}$ Whilst it is well known that

\footnotetext{
11 Notably, and unacknowledged by Ichikawa, out of an effective sample of 186 patients only two reported a cessation or restriction of visual dream imagery, leading Solms to conclude that the presence of this disorder in the neurological population was very low (1.1\%). I return to this point below.

12 Where this is understood as an inference to the best explanation (Lipton 2003).

13 Previous documentation of aphantasia include Galton (1880), Charcot (1889), James (1980), Faw (2009) and Solms (1997) who refers to a similar condition known as 'irreminiscence'.
} 
introspective reports regarding the vividness of mental imagery vary significantly amongst groups of individuals (McKelvie 1995; Phillips 2014), aphantasia is characterised by subjects - 'aphantasics' — who typically describe themselves as not just as having mental imagery of a reduced vividness, or impaired capacities for mental imagery generation limited to certain visual kinds, but as lacking the capacity to generate (typically visual) mental imagery altogether. ${ }^{14}$ The work on aphantasia, mental imagery and their neural bases is ongoing (Dawes et al. 2020; Winlove et al. 2018; Fulford et al. 2018), however, the condition has been documented in a series of recent studies (Zeman et al. 2010, 2015) which aim to identify its central neurobehavioural features. ${ }^{15}$ Produced as part of 'The Eye's Mind' AHRC Project at the Medical School at the University of Exeter, the first examines a form of imagery generation disorder exemplified in a single patientMX - who lost the ability to generate visual imagery abruptly, aged 65, four days after a coronary angioplasty (see Zeman et al. 2010). As part of the study, MX was subject to extensive psychometric testing in which he fell well within the normal range and tested negative for further cognitive deficits. What was surprising however, and served as the focus of this first study of aphantasia, was MX's normal performance on a range of visuo-spatial tests, typically thought to require conscious experience of mental imagery. ${ }^{16}$

In response to the publication of MX's case in the popular press (Zimmer 2010), a growing number of people have reported recognising MX's condition as a lifelong, as opposed to acquired, impairment. ${ }^{17}$ In the follow up study, Zeman and colleagues examine and describe the main neurobehavioural features of this congenital, life-long form of aphantasia (2015, 2016). Studying a group of 21 subjects who reported similar imagery deficits to MX's, the features of aphantasia were elicited via completion of the well documented Vividness of Visual Imagery Questionnaire (VVIQ). ${ }^{18}$ In addition to the expected finding that aphantasic subjects rated significantly lower on VVIQ scores compared 121 controls (see Fig. 1), the main finding was that aphantasic subjects, whilst reporting a sustained incapacity for imagery generation, nevertheless reported experience of involuntary mental imagery. This was evidenced both through the reported experience of wakeful involuntary flashbacks, such as unwanted visual images or earworms (48\%) but also, crucially, in the dream reports of aphantasic subjects, $81 \%$ of whom reported

\footnotetext{
14 Aphantasia thus understood is an imagery generation disorder (Farah 1984) distinguishable from visual memory disorders and visual agnosias (Zeman et al. 2015).

15 A larger systematic study of the experimental and neuropsychological features is currently being undertaken which will add to this data (Zeman, correspondence).

16 Taking an explanation of so-called 'blind imagination' as its focus, the study found that MX adopted different cognitive strategies from control subjects when performing these tasks. This has direct consequences for the long-standing 'imagery' debate (see Zeman et al. 2015; 153) which I do not discuss here.

17 Zeman et al. (2018) report 11,000 individual cases of extreme imagination (including aphantasia and hyperaphantasia—characterised by comparably high VVIQ scores, see below).

18 Marks (1973). See the supplementary materials online http://dx.doi.org/10.1016/j.cortex.2015.05.019. Aphantasia is operationally defined as performance of 16/81 on this scale (Zeman, correspondence).
} 


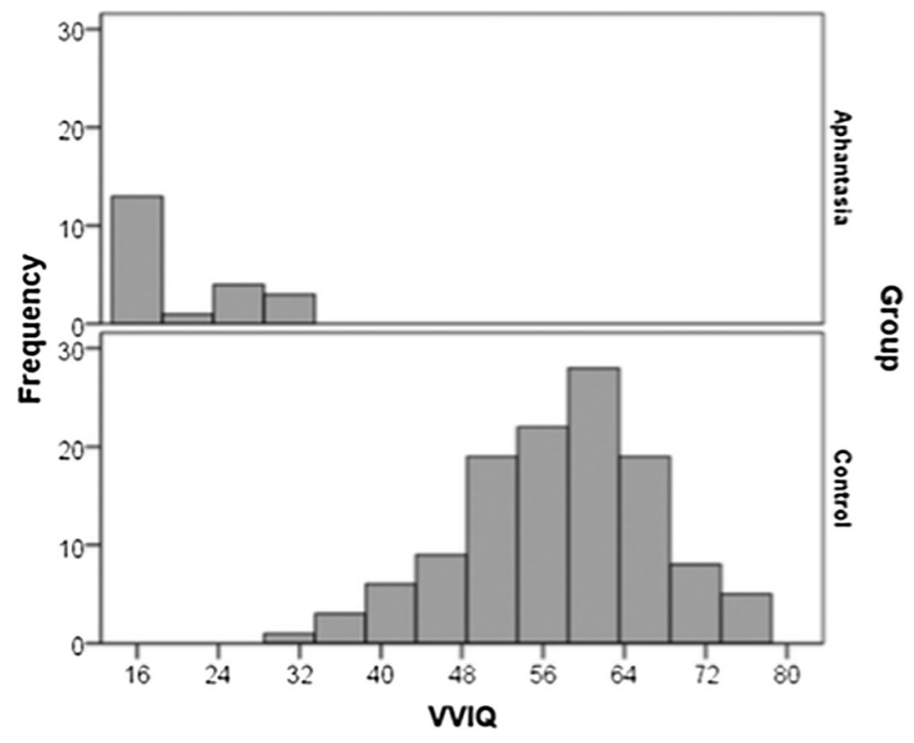

Fig. 1 Distribution of VVIQ scores among aphantasic subjects and control participants (Zeman et al. 2015, p. 379)

rich visual dreams. ${ }^{19}$ This led the authors to the following conclusion: that there is a "significant dissociation between voluntary and involuntary forms of mental imagery ( $p<.01$ McNemar Test)" (379, italics added). This is reflected in the author's previous discussion of patient MX who, while initially reporting a permanent loss of imagery generation, nevertheless regained the capacity to experience involuntary flashbacks as well as visual dream content within the same time period (2010;146-7). Here, Zeman et al. make a similar conjecture:

The initial loss of and subsequent recovery of dreaming in MX while voluntary imagery remained impaired, suggest that these two forms of imagery involve partially but incompletely overlapping neural networks, which is plausible in both cognitive and neural terms (154).

\section{The case against Ichikawa's imagination model}

As previously stated, Ichikawa's imagination model of dreaming is made up of three key components which jointly amount to the claim that dreams involve instances of agential sensory mental imagery as essential and constitutive components. This commits the proponent of Ichikawa's imagination model to the following: that to

\footnotetext{
19 Other notable findings include reported difficulties with autobiographical memory (68\%) and low effects on mood. This main finding with respect to visual dreaming and aphantasic subjects has recently been confirmed in a follow up study of the cognitive profile of aphantasia (Dawes et al. 2020). Here again, it was found that aphantasic individuals retain a capacity for rich visual dreaming, despite reporting dreams less frequently than control subjects. I return to this latter finding in the final section.
} 
the extent that any given dream has visual content at all, this can be accounted for solely in terms of such agential sensory mental imagery. ${ }^{20}$ In light of this, the problem that dream reports of aphantasic subjects raise for this view is straightforward. Faced with a description of aphantasic subjects-characterised in the congenital form as lacking the capacity to generate visual mental imagery in any agential capacity from birth — an imagination model of dreaming as outlined above would predict that these subjects would have dreams with little or no visual content. That is, if aphantasic subjects are correctly described as lacking the capacity to experience visual mental imagery when waking, and we grant Ichikawa's claims that (i), per imagery, visual dream content is to be understood as an instance of this kind of wake-type experience and (ii) per the methodological assumption raised by the psychological case, that this ought to be reflected in empirical case studiesthen we should expect that subjects with congenital aphantasia would report similar deficits with regard to the visual imagery experienced when dreaming. However, the findings of the current aphantasia studies go against this, providing evidence of multiple cases in which subjects report a sustained, lifelong loss of waking imagery whilst the capacity for rich visual dreaming is retained. The preliminary studies thus seem to disconfirm Ichikawa's theory, and in doing so, problematically lend support to alternative accounts which do not make such predictions (such as the hallucination model of dreaming) which the imagination model was meant to replace.

A similar pattern emerges on examination of acquired aphantasia in patient MX. Whilst initially MX's dream reports seem to accord with the predictions made by the imagination model viz. that a sustained loss in the generation and experience of visual mental imagery would be accompanied by a parallel reduction in visual dream content, the long term finding that MX regained the capacity for visual dreams and involuntary imagery without also regaining the former (in conjunction with the dream reports of congenital subjects) provides an explanatory burden for the proponent of the imagination model of dreaming: If the imagination model of dreaming is correct, why is it that aphantasic subjects, who lack the capacity to generate and exercise agency over their visual mental imagery, are able to have dreams with visual content?

The empirical challenge that individuals with aphantasia and their dream reports raise for Ichikawa's imagination model relies on the acceptance of four broad claims:

1. Subjects with aphantasia lack the agential capacity to generate and consciously experience sensory mental imagery.

\footnotetext{
${ }^{20}$ That is not to say that Ichikawa isn't entitled to claim that there are non-visual (tactile, auditory etc.) forms of mental imagery involved in dreams, nor that there cannot be dreams devoid of visual content. This is only to say that, to the extent that they $d o$, these can be accounted for solely in terms of visual mental imagery generation. If the visual content were to be accounted for only partly by imagery and in part by other kinds of experience, this would result in a version of a pluralist thesis. I take it that, as a variety of a 'reductive' account of dreams (Rosen 2012), the proponent of the imagination model is opposed to this latter claim.
} 
2. Visual imagery in dreams is to be understood and accounted for solely in terms of imagery of this kind.

3. Dream reports accurately reflect dream experience such that aphantasic dreams are correctly described as having visual content.

4. An adequate ontology of dreams must have the resources to account for empirical considerations similar to those raised by the dream reports of aphantasics.

If the challenge-namely, that recent empirical studies provide psychological consideration better accommodated by rival accounts of dreams - is to be deflected then one of these claims must be rejected.

A full assessment of the arguments for and against these claims, and the underlying methodological principles these depend upon, goes well beyond the scope of this paper. However, (1) reflects an uncontroversial claim regarding what the VVIQ studies of subjects with aphantasia confirm, along with a plausible assumption about the general nature of introspection (a claim which, it should be stressed, is relied upon in much of contemporary consciousness science). ${ }^{21}$ (2) as discussed, follows from the endorsement of Ichikawa's imagination model of dreaming. This leaves the proponent of Ichikawa's imagination model with the possibility of rejecting claims (3) or (4). In addition to the fact that both enjoy broad acceptance in the surrounding literature, and thus whose rejection would require significant independent argument, the more pertinent problem for Ichikawa when faced with the prospect of rejecting these claims is that both are relied upon in the existing psychological and-in the case of (3) - conceptual arguments Ichikawa utilises in order to motivate the position to begin with. ${ }^{22}$ As discussed at the end of 3.2, Ichikawa's endorsement of his psychological case conveys a commitment to the claim that it is an expectation of philosophical accounts of dreams that they are supported by, or at least able to accommodate, empirical cases like these. As such, the rejection of (3) or (4) comes at a great cost to Ichikawa, in removing or significantly weakening the case for the position that we started with. Collectively, the discussion here can be seen as resulting in the following dilemma for the proponent of the imagination model: to either claim that these kinds of empirical considerations are irrelevant to discussions of dream ontology—on the basis of denying either (3) or (4) - and thus abandon the previous psychological case in favour of the model, or grant instead that aphantasia constitutes a compelling empirical case which alternative models of dreaming can better accommodate.

\footnotetext{
21 The claim also has empirically plausibility—see Keogh and Pearson (2018). Pearson and Keogh attempt to refute an alternative explanation for congenital aphantasia according to which aphantasia results from poor metacognition as opposed to a visual imagery deficit (that is, that aphantasic subjects do have visual images in their minds but are in some sense 'blind' to them). They conclude that congenital aphantasia is correctly characterised as a disorder of visual/sensory mental imagery, and I grant this here.

22 See Windt (2010, 2013, 2015) and Windt and Metzinger (2007) for an independent defense of the reliability of dream reports in ideal conditions. Denial of (4) is also independently implausible for several reasons, the most notable of which concerns the recent debate over the methodology of metaphysics and its relationship to science (see Paul 2012). On this view, accommodation of empirical considerations would not be a mere or optional virtue of competing theories of dreams, but is in fact demanded by acceptance of the claim that the metaphysics of mind proceeds via inference to the best explanation.
} 
Could a proponent of Ichikawa's theory not object here that (2) does not follow from Ichikawa's theory, given his claim that dream imagery results from the exercise of a type of mental agency which does not require voluntary control? That is, that the imagination model is not committed to the claim that visual dream mentation is to be accounted for solely in terms of the sort of mental imagery which is lacking in the aphantasaic case? The lack of elaboration and defense of this account of mental agency as that which is subject to the will-and the criterion of 'making sense to try to banish' which is meant to account for it-makes it difficult to respond to this line of argument. ${ }^{23}$ However, an objection to this line of response can be raised which targets the independent plausibility of Ichikawa's voluntaryinvoluntary agency distinction and its ability to secure an agentialist theory of imagination (and thus, the appeal to this distinction in response to this challenge). This results from the following: any agentialist account which aims to accommodate dreams and involuntary imaginative episodes requires a notion of agency which is (i) weak enough to not rule out dreams and involuntary imaginings as bona fide instances of imagination and (ii) is simultaneously robust such as to be sufficient to distinguish involuntary imaginings from other typical non-agential mental phenomena (perception, hallucinations etc.). The worry then, simply stated, is that it is not obvious that Ichikawa is successful in providing such an account. That is, one might think that it is neither clear that the voluntary-involuntary distinction is weak enough to secure dreams within its purview (how plausible is it, for example, that dreams are really things that we do involuntarily?) nor that the "making sense to attempt to banish' criterion is sufficient to distinguish between instances of involuntary imagination from other mental phenomena (does it not similarly make sense to attempt to banish hallucinatory experiences?). As such, the objection goes, appeal to this account here is unwarranted. In the absence of further elucidation and defense of this notion of agency, Ichikawa's claim collapses into the thesis described in (2). ${ }^{24}$

The foregoing argument can thus be seen as presenting a dilemma for proponents of Ichikawa's theory, resulting from a distinction between a strong and weak view of the relationship between mental agency and visual imagery in dreams. That is, either the proponent of the imagination model of dreaming can claim that notion of agency at play here is strong-being comparable to that which is lacking in subjects with aphantasia - which leaves Ichikawa vulnerable to the empirical challenge, or the relevant notion of agency is weak. While this deflationary analysis may avoid the empirical challenge, this account-grounded in the notion of agency as that

\footnotetext{
23 See Ichikawa (2009, pp. 107, 116).

24 I return to this objection in the final section, where I suggest an empirical means of testing its viability. However, it is worth noting here that one might think that concerns remain even if a relevant notion of agency can be conceptually secured. For example, one might argue that the "significant dissociation between voluntary and involuntary forms of mental imagery"' Zeman et al. report (2015, p. 379) places significant pressure on Ichikawa's claim that involuntary forms of imagery shares and inherits the agential nature of the voluntary imaginings which drives agential accounts of imagination. At the very least, this raises a question for Ichikawa: if recent empirical data pushes us to accept a view on which voluntary and involuntary imagery are, to a large extent, neurally distinct, why think that the claim that involuntary imagination shares the agential nature of voluntary imagination remains a plausible one?
} 
which is 'subject to the will'-leaves the proponent of Ichikawa's view of dreaming with a theory of imagination which lacks independent plausibility; being unable to satisfy the independent requirements on an adequate philosophical theory of imagination. Either way, the argument goes, this model of dreaming ought to be rejected. $^{25}$

\section{An inactive imagination model of dreaming}

Are there other alternatives open to the proponent of the imagination model of dreaming? I have argued that the dream reports of aphantasic subjects pose a problem for Ichikawa's model of dreaming insofar as Ichikawa is committed to the claim (2) that dreams essentially involve, or constitute instances of, experiences of agential forms of sensory mental imagery. That is, visual mental imagery which is in an important sense under our agential control. This follows as a consequence of Ichikawa's characterisation and individuation of imagination more broadly, as that which is necessarily subject to the will. Recent literature however suggests that Ichikawa's formulation is not the only way of characterising the imagination model of dreaming. Here, I argue that the best response to the case studies presented in Sect. 2 for a proponent of an imagination model of dreaming is to reject thesis (2) above in favour of a modified claim. This allows the proponent of this model to avoid the dilemma just presented and retain the psychological case Ichikawa outlines in favour of an imagination model of dreaming. ${ }^{26}$

Motivated by the need to provide a philosophical analysis of the state of wakeful consciousness, as an explanatorily preeminent condition relative to non-wake states, the alternative account of dreaming receiving attention in recent literature starts from an analysis of the wakeful condition as necessitating a kind of practical self-

\footnotetext{
${ }^{25}$ Here the following thought may arise. It is commonly held that the capacity for visual dreaming can be preserved in blind subjects if eyesight is lost after the age of 7 years. Does adherence to this argument against Ichikawa's model of dreaming also commit one to an analogous argument with respect to hallucination models of dreaming - that is, commit one to the claim that empirical findings about the dream reports of blind subjects similarly threaten theories which state that dreams are essentially perceptinvolving hallucinations? This is an interesting line of thought. It does, however, elicit an obvious line of response on behalf of the hallucination theorist, which suggests a negative answer to this question. This takes as its basis the well-known distinction between 'perception' (as implicated in blindness) and the wider category of 'visual experience'. Here, the thought is that, unlike the case of aphantasia and sensory imagination, the fact that one's capacity to visually perceive has been disabled (in blindness) does not entail that the subject in question cannot undergo visual experiences of any sort, because these are, crucially, two distinct phenomena. That is, there are percept-involving visual experiences-namely, hallucinations - which are not (according to most theories) perceptions. The hallucination theorist can thus accommodate this finding via a line of argument which is unavailable to the imagination theorist, as there is no obvious, analogous distinction in the case of sensory imagination and aphantasia. Thank you to an anonymous reviewer for bringing my attention to this issue.

26 A note of clarification: the suggestion in this paper is not that this inactive imagination model of dreaming is incontrovertibly correct. That is, I do not take myself to present an adequate defense of this view here. Rather, the claim is that there is-pending further work (and examination of the arguments for it presented in the cited articles below) - a viable response to the empirical challenge which can be taken up by the proponent of the imagination model.
} 
knowledge which results from the exercise of autonomous mental agency (O'Shaughnessy 2000, 2002). ${ }^{27}$ According to this analysis, the constitutive difference between wakeful and non-wakeful conditions (in this case, dreaming) is given in terms of the (in)capacity to exercise agency over our mental lives-that is, a capacity or ability to perform mental actions-which, it is claimed, is responsible for enabling the distinctive and immediate sort of self-knowledge (knowledge of 'what we are up to') characteristic of wakeful consciousness (Soteriou 2017, Crowther 2018). ${ }^{28}$ In O'Shaughnessy's words (2002;426, see also Soteriou 2017) the suggestion here is that "Consciousness [wakeful consciousness] necessitates an overall mental activeness, for the reason that the conscious [i.e. the awake] are in control of the overall movement of their own minds, and the dream is an essentially inactive phenomenon', (emphasis added).

How does this help the imagination theorist with respect to dreaming? From this analysis of wakeful consciousness, a general claim regarding the nature of dreaming follows: that dreaming involves the temporary incapacitation of our ability to exercise mental agency. It is thus an 'essentially inactive' phenomenon. When combined with (i) imagery, this provides us with the following:

$(2 *)$ dreaming essentially involves instances of passive, non-agential forms of imagination. $^{29}$

This is usually combined with the further claim that the episodes of inactive or nonvoluntary imagining constitutive of dreaming are characterised by an appearance or illusion of being mentally active. Soteriou (2017) sums the proposal as follows: "In short, [in the dream state] one suffers from a sort of mental paralysis-a form of mental paralysis that doesn't even allow for the possibility of failed attempts to exercise agency over one's thinking. But it is a form of mental paralysis that is accompanied by the illusion of agency - the illusion of seeming to affirm, seeming to judge seeming to decide, seeming to be mentally active (13; emphasis added).

Insofar as this model rejects Ichikawa's characterisation of imagination as necessarily subject to the will, the alternative account of the imagination model of dreaming is not committed to the central claim of Ichikawa's account viz. that dreams constitutively involve the same form of agential imagination which is lacking in the aphantasia subjects. Given that on this model, the capacity to imagine

\footnotetext{
27 See O'Shaughnessy (2000), Crowther (2018) for an explanation of this connection in terms of the 'internal intelligibility' of the stream of consciousness.

28 This is meant to be neutral with regard to whether this claim is to be accounted for solely in terms of dispositions of agency or broadly in terms of differences in general capacitation not limited to mental agency (Crowther 2018). The latter claim is all that is required.

29 See the aforementioned articles for discussion of this account, which is proposed as a theory of nonlucid dreams. That is, in order to account for lucid dreams (see later) this view is usually accompanied by the claim that dreaming - and sleep mentation generally-is a non-unitary phenomenon which allows for hybrid states of consciousness (Voss and Hobson 2014; Bayne et al. 2016; Howhy and Bayne et al. 2016). That is, they claim that "during lucid dreams, the dreaming subject becomes aware that the events she is imagining are not real, and this is precisely because at that point during sleep the subject's ability to exercise agency over her mental life is reinstated, albeit in a limited, degraded form" (Soteriou 2017, p. 12). I leave it open whether this argument is ultimately successful.
} 
and the capacity to exercise agency over our mental lives comes apart, it allows for and, to the extent that it defines dreaming in terms of this incapacity for mental agency, predicts that agents who lack the capacity to perform mental acts with regard to visual imagination (namely, aphantasic subjects) may nevertheless retain the capacity to visually dream. The implication of this claim should be obvious: on this variation of the imagination model-where (2) is replaced with $(2 *)$ - the empirical challenge raised by aphantasia fails to hold.

As this amounts to a rejection of Ichikawa's (iii) claim—namely, his agentialist theory of imagination-proponents of the inactive imagination model need to supplement this account of dreaming with an alternative theory of imagination which, as stated earlier, can adequately account for the various desiderata on contemporary philosophical accounts of imagination. ${ }^{30}$ While the foregoing argument depends on the availability of such an account, it also serves a broader purpose-highlighting the role and dialectical importance of philosophical theories of imagination in the recent debate over dreams which has previously been underappreciated.

\section{Suggestions for future research}

\subsection{Extreme imagination and competing theories of dreams}

Thus far, I have been considering the implications that the dream reports of subjects with aphantasia have for Ichikawa's agentialist imagination theory of dreaming. But what, if any, is the broader theoretical significance of these findings for the philosophy and science of consciousness? This section includes a discussion of two proposals which serves to situate the recent studies of aphantasia in the wider context. Turning first to the implications of the foregoing discussion of the philosophy of mind and consciousness. Assessing these requires us to answer the following questions: first, how does the empirical challenge I present against an active imagination model and in favour of inactive account of dreaming relate to the previous empirical considerations Ichikawa offers in support of an imagination model of dreaming? Are the results from the aphantasia studies and those from Solms' and Foulkes' studies on dream development and dream pathology congruous - that is, do they, when considered together, provide a strong case for an inactive imagination model of dreaming, or are they instead suggestive of a more disparate evidential picture? Second and relatedly, we are now in a position to ask how the empirical considerations raised by aphantasia relate to alternative theses concerning the ontological constitution of dreams. In the previous section, I argued that the empirical argument based on dream reports of aphantasia could be offset if

\footnotetext{
${ }^{30}$ Recent literature suggests that this ought to be supplemented by a dependency theory of imagination, which provides an analysis of imagination in terms of their phenomenal resemblance and ontic dependency on perceptual experiences (Martin 2002; Peacocke 1985; Soteriou 2013; cf. Nanay 2016; Noordhof 2002). However, it seems that an epistemological account of imagination (O'Shaughnessy 2000; Sartre 1940) would serve the imagination theorist just as well here.
} 
an inactive imagination theory of dreaming was endorsed, but can this particular empirical consideration do any further positive work in this context? In other words, what does the finding that aphantasic subjects have visual dreams mean for competing analyses of dreams?

At first glance, there seems to be a tension between Ichikawa's psychological case for the imagination model and the dream reports of aphantasics discussed here. This arises as a result of Solms' clinico-anatomical study of dream pathologies described in Sect. 3.2. There, to recall, Solms reported that patients with dream pathologies in which visual dream imagery was lost describe precisely analogous deficits in waking visual imagery (Solms 1997, pp. 93-102, Ichikawa 2016, p. 254). Insofar as the dream reports of aphantasics constitute multiple cases in which waking visual imagery is lost while dream visual imagery is retained, these results appear to be in tension with this new data; thus, when considered collectively, these appear to be suggestive of a disparate evidential picture with respect to the thesis that dreams constitutively involve instances of sensory imagination.

This initial impression is, however, misleading. Interestingly-and unacknowledged by Ichikawa - out of the effective sample of 186 patients Solms examined, only two reported a cessation or restriction of visual dream imagery (and the parallel loss of visual waking imagery), leading Solms to the early conclusion that the presence of this particular dream disorder in the neurological population was very low $(1.1 \%)$. The small number of patients examined constitute an obvious, and previously unnoted, limitation to Ichikawa's psychological argument. Nonetheless, this feature of the study provides a means of rendering Solms' results compatible with Zeman et al.'s finding that $81 \%$ of the aphatnasics studied report rich visual dreams. That is, Zeman et al.'s finding here is consistent with the correlational data Solms reports in his study, in which it is acknowledged that this applies only to a small number of patients. Instead of opposing Solms' research findings, the dream report data of aphantasics can thus be seen as a welcome addition to Solms' early results on visual imagery dream disorders and its relation to waking visual imagery deficiencies, demonstrating that the correlational pattern Solms describes is characteristic of exceptions to aphantasic cases and not the norm. ${ }^{31}$

Turning now to the second question. What significance, if any, does the finding that aphantasic subjects have visual dreams have for competing analyses of dreams? A number of more comprehensive studies on aphantasia and other forms of extreme imagination are currently underway. Thus far, these studies on extreme imagination are suggestive of a number of notable findings. Most importantly, they reveal that a positive correlation holds between both (i) the absence of waking visual imagery and loss of dream imagery and (ii) the presence of hyperaphantasia and particularly

\footnotetext{
31 What explains these cases? Should we not expect that all aphantasics lack visual dream imagery? The imagination proponent owes us an explanation here. One suggestion-open to future empirical confirmation-is that the terms 'aphantasia' and 'hyperaphantasia' do not represent binary categories but are best understood as poles on an imagery vividness continuum (a hypothesis supported by McKelvie 1995 as well as a recent study on individual differences in aphantasic subjects from Dawes et al. 2020). The suggestion then is that those aphantasics reporting no visual dream imagery fall at the extreme end of this spectrum, while those reporting visual dream imagery correspond to more 'moderate' forms of aphantasia.
} 
vivid visual dreams, compared to normal controls. ${ }^{32}$ When considered in conjunction with the main finding of Zeman et al. discussed in this paper, this places an explanatory burden on alternative prominent theories of dreams-such as the hallucination (Hobson 1988) and recent sui-generis theories (Windt 2010; 2015): why, if there is no tight ontological connection between dream mentation and sensory imagination, as these theories maintain, are subjects with aphantasia more likely than those with average or vivid imagery to report absence or reduction of visual dreaming? Answering this question and collecting further data which sheds light on its viability, is the next obvious step for philosophers working on dreams who aim to provide satisfactory and empirically adequate solutions to the conceptualisation problem.

\subsection{Aphantasia and lucid dreaming: a testable empirical hypothesis}

An obvious datum for any conceptual theory of dreaming, and one which is pertinent to the issues discussed in this paper, is the phenomenon of lucid dreaming — dreams in which subjects become aware that they are dreaming and, in some cases, are able to manipulate and control their dream content (La Berge 2004; Voss et al. 2009). Insofar they provide opportunities in which subjects can reflect, introspect and subsequently report the content of their dreams in greater detail, experimental paradigms investigating lucid dreams continue to be at the forefront of empirical dream research. ${ }^{33}$ As an agentive state of consciousness, in which a subject's capacity for mental agency is clearly retained in some form, lucid dreams also play an important role in motivating Ichikawa's agentialist account of the imagination theory, and serve as an obvious counterexample to the inactive imagination model of dreaming. ${ }^{34}$ In addition to this initial role however, the rediscovery of aphantasia presents lucid dream research with a further empirical function. When lucid dreaming is considered in the context of the recent studies of aphantasics and their visual dream reports, the following question arises: can subjects with aphantasia also lucid dream in a visual sense? Currently, no cases of lucid dreaming in subjects with aphantasia have been reported. ${ }^{35}$ However, the

\footnotetext{
32 Dawes et al. (2020) and Zeman (correspondence).

33 Voss et al. (2018); Windt and Voss (2018) Saunders et al. (2016) include recent meta-analyses and summaries of this work. Here, lucid dreams are characterised by the three dissociable features : (i) the presence of subject insight (a conscious awareness that one is dreaming) (ii) control (manipulation of dream content and narrative) and dissociation from one's dream experience (such as seeing the dream as if it were playing on a screen, or viewing one's self from the outside).

34 Ichikawa (2009, pp. 116-117). See footnote 28 for a discussion of lucid dreaming and the inactive account of dreaming which involves the hypothesis that lucid dreaming is a hybrid phenomenon (Voss et al. 2018; Soteriou 2017).

35 Zeman (correspondence). It would also be useful to conduct further dream studies of aphantasics who don't lucid dream. That is, the following question also appears to be empirically testable: do subjects with aphantasia report an ability to attempt to banish-in Ichikawa's sense-their visual imagery whilst dreaming? This would, if the finding is negative, lend greater support to the argument presented above. Whilst research on the phenomenology and sense of agency in dreams is currently in early stages (see Rosen 2015 for a review), this presents a promising line of work for future research.
} 
availability and empirical examination of such cases could greatly improve,- - or, alternatively, weaken - the case in favour of the inactive imagination model of dreaming presented in this paper. That is, if it found that aphantasic subjects generally report an inability to lucid dream this would-on the assumption that the capacity to (or otherwise learn how to) lucid dreaming is generally available in typical samples of the population-lend empirical support to the thesis that dreams constitutively involve inactive forms of imagination. ${ }^{36}$ Conversely, if aphantasia subjects generally retain the capacity for lucid dreaming (relative to its uptake and presence in control groups) - and those lucid dreams contain visual content- the inactive imagination model would - on the assumption that dreams are homogeneous in nature- be empirically disconfirmed. This potential to facilitate further empirical work, along with the philosophical applications discussed in the previous section imbues aphantasia with a wider theoretical significance in the context of the conceptualisation problem which goes beyond the repudiation of Ichikawa's theory of dreaming, and provides philosophers and psychologists with an exciting new avenue of dream research.

Acknowledgements I owe a large debt of gratitude to Matt Soteriou for many enlightening discussions and comments on this article. I would also like to thank Jonathan Birch, Adrian Boutel, two anonymous reviewers at Philosophical Studies and the audience members at the Dreams, Hallucinations and Imagination workshop, the ASSC 23 and the European Society for Philosophy and Psychology meeting in Athens for their helpful comments and feedback.

Open Access This article is licensed under a Creative Commons Attribution 4.0 International License, which permits use, sharing, adaptation, distribution and reproduction in any medium or format, as long as you give appropriate credit to the original author(s) and the source, provide a link to the Creative Commons licence, and indicate if changes were made. The images or other third party material in this article are included in the article's Creative Commons licence, unless indicated otherwise in a credit line to the material. If material is not included in the article's Creative Commons licence and your intended use is not permitted by statutory regulation or exceeds the permitted use, you will need to obtain permission directly from the copyright holder. To view a copy of this licence, visit http:// creativecommons.org/licenses/by/4.0/.

\footnotetext{
${ }^{36}$ Early support for this claim is found in a recent study on aphantasia from Dawes et al. (2020), who report that 'aphantasic individuals also reported experiencing lower awareness and control during their dreams [compared to control subjects]' (6). The most relevant phenomenon here of course are lucid dreams in which the subject is able to control and manipulate her visual dream imagery to some degree (whether or not lucid dreams where insight is present but not control could be included in this sort of study will largely depend upon the-currently open question-of know exactly insight should be understood, especially with respect to mental agency-Voss 2016; Kühle 2014). While control of this kind is less frequent in the 'naturally occurring' lucid dreams found mostly in adolescents (Voss et al. 2012; Voss and Hobson 2014) there is currently good evidence that control-involving lucid dreaming in adults is a learnable skill or ability which can be improved with practice (La Berge 2007; Schredl and Erlacher 2011; Kühle 2014). The proposal I am making would thus require researchers to c2014ompare the ability to uptake this form of lucid dreaming in a large sample of aphanatasics, and compare this to the percentage of people able to learn this skill in the general population (that is, my proposal here is consistent with the claim that a proportion of aphantasics and non-aphantasic subjects will not exercise lucid dream control for reasons which have nothing to do with Ichikawa's hypothesis). Thank you to an anonymous referee for prompting me to clarify this proposal.
} 


\section{References}

Allen, K. (2015). Hallucination and imagination. Australasian Journal of Philosophy, 93(2), 287-302.

Bayne, T., Hohwy, J., \& Owen, A. M. (2016). Are there levels of consciousness? Trends in Cognitive Sciences, 20(6), 405-413. https://doi.org/10.1016/j.tics.2016.03.009.

Charcot, J. M. (1889). Clinical lectures on diseases of the nervous system (Vol. 3). London: The New Sydenham Society.

Crowther, T. (2018). Experience, dreaming, and the phenomenology of wakeful consciousness. In F. Dorsch, F. MacPherson, \& M. Nida-Rumelin (Eds.), Phenomenal presence. Oxford: Oxford University Press.

Dawes, A. J., Keogh, R., Andrillon, T., et al. (2020). A cognitive profile of multi-sensory imagery, memory and dreaming in aphantasia. Scientific Reports, 10, 10022.

Dennett, D. C. (1976). Are dreams experiences? Philosophical Review., 85(2), 151.

Descartes, R. (1984). Philosophical writings of descartes, Volumes I-III, (J. Cottingham, R. Stoothoff, \& D. Murdoch, Trans.). In J. Cottingham, R. Stoothoff, D. Murdoch, \& A. Kenny (Vol. III ed), Cambridge: Cambridge University Press.

Dorsch, F. (2012). The unity of imagining. Berlin: De Gruyter.

Dorsch, F. (2015). Focused daydreaming and mind-wandering. Review of Philosophy and Psychology, 6(4), 791-813.

Farah, M. J. (1984). The neurological basis of mental imagery: A componential analysis. Cognition, 18, $245-272$.

Faw, B. (2009). Conflicting intuitions may be based on differing abilities-Evidence from mental imaging research. Journal of Consciousness Studies, 16, 45-68.

Foulkes, D. (1982). Children's dreams: Longitudinal studies. New York: Wiley.

Foulkes, D. (1996). Dream research: 1953-1993. Sleep, 19, 609-624.

Foulkes, D. (1999). Children's dreaming and the development of consciousness. Cambridge, MA: Harvard University Press.

Fulford, J., et al. (2018). The neural correlates of visual imagery vividness e An fMRI study and literature review. Cortex. https://doi.org/10.1016/j.cortex.2017.09.014.

Galton, F. (1880). Statistics of mental imagery. Mind, 5, 301-318.

Hobson, J. A. (1988). The dreaming brain. New York, NY: Basic Books.

Hobson, J., Pace-Schott, E. F., \& Stickgold, R. (2003). Dreaming and the brain: Toward a cognitive neuroscience of conscious states. In E. F. Pace-Schott, M. Solms, M. Blagrove, \& S. Harnad (Eds.), Sleep and dreaming: Scientific advances and reconsiderations (pp. 793-842). Cambridge: Cambridge University Press.

Ichikawa, J. (2008). Scepticism and the imagination model of dreaming. The Philosophical Quarterly, $58(232), 519-527$.

Ichikawa, J. (2009). Dreaming and imagination. Mind and Language., 24(1), 103-121.

Ichikawa, J. (2016). Imagination, dreaming, and hallucination. In Amy Kind (Ed.), Routledge handbook of the philosophy of imagination (pp. 149-162). London: Routledge.

James, W. (1980). The principles of psychology (Vol. 2). London: Dover Publications.

Keogh, R., \& Pearson, J. (2018). The blind mind: No sensory visual imagery in aphantasia. Cortex. https://doi.org/10.1016/j.cortex.2017.10.012.

Kosslyn, S. M., Thompson, W. L., \& Ganis, G. (2006). The case for mental imagery. Oxford: Oxford University Press.

Kriegel, U. (2015). Perception and Imagination. In S. Miguens, G. Preyer, \& C. Bravo Morando (Eds.), Pre-reflective consciousness: Sartre and contemporary philosophy of mind (pp. 245-276). Abingdon: Routledge.

Kühle, L. (2014). Insight: What is it, Exactly? Open MIND. Frankfurt am Main: MIND Group.

La Berge, S. (2004). Substances that enhance recall and lucidity during dreaming. U.S. Patent Application 10/604, 138.

La Berge, S. (2007). Lucid dreaming. In D. Barrett \& P. McNamara (Eds.), The new science of dreaming, Volume 1: Biological aspects (pp. 307-328). Westport: Praeger Perspectives.

Lipton, P. (2003). Inference to the best explanation. Abingdon: Routledge.

Malcolm, N. (1956). Dreaming and skepticism. Philosophical Review, 65(January), 14-37.

Marks, D. F. (1973). Visual imagery differences in the recall of pictures. British Journal of Psychology, 64, 17-24. 
Martin, M. G. F. (2001). Out of the past: Episodic recall as retained acquaintance. In C. Hoerl \& T. McCormack (Eds.), Time and memory (pp. 257-284). Oxford: Oxford University Press.

Martin, M. G. F. (2002). The transparency of experience. Mind and Language, 17, 376-425.

Martin, M. G. F. (2004). The limits of self-awareness. Philosophical Studies, 120, 37-89.

Martin, M. G. F. (2006). On being alienated. In T. S. Gendler \& J. Hawthorne (Eds.), Perceptual experience. Oxford: Oxford University Press.

McGinn, C. (2004). Consciousness and its objects. Oxford: Oxford University Press.

Mckelvie, S. (1995). The VVIQ as a psychometric test of individual differences in visual imagery vividness: A critical quantitative review and plea for direction. Journal of Mental Imagery, 19, $1-106$.

Nanay, B. (2016). Imagination and Perception. In Amy Kind (Ed.), Routledge Handbook of the philosophy of imagination. Abingdon: Routledge.

Noordhof, P. (2002). Imagining objects and imagining experiences. Mind and Language, 17(4), 426-455.

O'Shaughnessy, B. (2000). Consciousness and the world. Oxford: Oxford University Press.

O'Shaughnessy, B. (2002). Dreaming. Inquiry: An Interdisciplinary Journal of Philosophy, 45(4), 399-432.

O'Shaughnessy, B. (2008). The will: A dual aspect theory. Cambridge: Cambridge University Press.

Paul, L. A. (2012). Metaphysics as modelling: the handmaiden's tale. Philosophical Studies, 160(1), $1-29$.

Peacocke, C. (1985). Imagination, experience and possibility. In J. Foster \& H. Robinson (Eds.), Essays on Berkeley (pp. 19-35). Oxford: Clarendon Press.

Phillips, I. (2014). Lack of imagination: Individual differences in mental imagery and the significance of consciousness. In M. Sprevak \& J. Kallestrup (Eds.), New waves in philosophy of mind. New waves in philosophy. London:Palgrave Macmillan. https://doi.org/10.1057/9781137286734_14.

Revonsuo, A. (2005). Inner presence: Consciousness as a biological phenomenon. Cambridge, MA: MIT Press.

Rosen, M. (2012). Dream pluralism: a philosophy of the dreaming mind. Thesis (PhD) Macquarie University, Faculty of Human Sciences, Department of Cognitive Science 2012. Available from: http://hdl.handle.net/1959.14/284236.

Rosen, Melanie. (2013). What I make up when I wake up: Anti-experience views and narrative fabrication of dreams. Frontiers in Psychology, 4, 514. https://doi.org/10.3389/fpsyg.2013.00514.

Rosen, M. (2015). I'm thinking your thoughts while I sleep: Sense of agency and ownership over dream thought. Psychology of Consciousness: Theory, Research, and Practice., 2(3), 326-339.

Rosen, M. (2019). Dreaming of a stable world: Vision and action in sleep. Synthese, https://doi.org/10. 1007/s11229-019-02149-1.

Sartre, J. P. (1940, 2012). The Imagination. Routledge.

Saunders, D. T., Roe, C. A., Smith, G., \& Clegg, H. (2016). Lucid dreaming incidence: A quality effects meta-analysis of 50 years of research. Consciousness and Cognition, 43, 197-215. https://doi.org/10. 1016/j.concog.2016.06.002.

Schredl, M., \& Erlacher, D. (2011). Frequency of lucid dreaming in a representative German sample. Perceptual and Motor Skills, 112(1), 104-108.

Sinhababu, N. (2016). Imagination and belief. In A. Kind (Ed.), The Routledge handbook of philosophy of imagination (pp. 111-123).

Solms, M. (1997). The neuropsychology of dreams: A clinico-anatomical study. Hillsdale, NJ: Erlbaum.

Solms, M., \& Turnbull, O. (2002). The brain and the inner world. New York: Other Press LLC.

Sosa, E. (2005). Dreams and philosophy. Proceedings and Addresses of the American Philosophical Association, 79(2), 7-18.

Sosa, E. (2007). A virtue epistemology: Apt belief and reflective knowledge (Vol. I). Oxford: Clarendon Press.

Sosa, E. (2009). Reflective knowledge. Oxford: Oxford University Press.

Soteriou, M. (2013). The mind's construction: The ontology of mind and mental action. Oxford: Oxford University Press.

Soteriou, M. (2017). Dreams, agency, and judgement. Synthese. https://doi.org/10.1007/s11229-0171496-7.

Sutton, J. (2009). Dreaming. In J. Symons \& Paco Calvo (Eds.), Routledge companion to the philosophy of psychology. Abingdon: Routledge.

Thompson, E., \& Batchelor, S. (2014). Waking, dreaming, being: Self and consciousness in neuroscience, meditation, and philosophy. Cambridge: Cambridge University Press. 
Voss, U. (2016). Reflections on insight: a reply to Lana Kühle. Johannes Gutenberg-Universität Mainz.

Voss, U., \& Hobson, A. (2014). What is the state-of-the-art on lucid dreaming? - Recent advances and questions for future research. Frankfurt am Main: MIND Group.

Voss, U., D’Agostino, A., Kolibius, L., Klimke, A., Scarone, S., \& Hobson, J. A. (2018). Insight and dissociation in lucid dreaming and psychosis. Frontiers in Psychology. https://doi.org/10.3389/ fpsyg.2018.02164.

Voss, U., Frenzel, C., Koppehele-Gossel, J., \& Hobson, A. (2012). Lucid dreaming: An age-dependent brain dissociation. Journal of Sleep Research, 21(6), 634-642.

Voss, U., Holzmann, R., Tuin, I., Hobson, A. J., \& Dreaming, L. (2009). A state of consciousness with features of both waking and non-lucid dreaming. Sleep, 32(9), 1191-1200. https://doi.org/10.1093/ sleep/32.9.1191.

Walton, K. L. (1990). Mimesis as make-believe: On the foundations of the representational arts. Harvard: Harvard University Press.

Windt, J. M. (2010). The immersive spatiotemporal hallucination model of dreaming. Phenomenology and the Cognitive Sciences., 9(2), 295-316.

Windt, J. (2013). Minding the dream self: Perspectives from the analysis of self-experience in dreams. Behavioral and Brain Sciences, 36(6), 633-633. https://doi.org/10.1017/S0140525X13001477.

Windt, J. M. (2015). Dreaming: A Conceptual Framework for Philosophy of Mind and Empirical Research.

Windt, J. M., \& Metzinger, T. (2007). The philosophy of dreaming and self-consciousness: What happens to the experiential subject during the dream state? In Deirdre Barrett \& Patrick McNamara (eds.). The New Science of Dreaming. Vol 3: Cultural and Theoretical Perspectives. Greenwood Publishing Group. pp. 193-247.

Windt, J., \& Voss, U. (2018). Spontaneous thought, insight, and control in lucid dreams. In K. Christoff \& K. Fox (Eds.), The Oxford handbook of spontaneous thought: Mind-wandering, creativity, and dreaming. Oxford: Oxford University Press.

Winlove, C. P., Milton, F., Ranson, J., Fulford, J., MacKisack, M., Macpherson, F., et al. (2018). The neural correlates of visual imagery: A co-ordinate-based meta-analysis. Cortex, 105, 4-25.

Wittgenstein, L. (1967). Zettel. Berkeley: University of California Press.

Zeman, A. Z. J., Della Salla, S., Torrens, L. A., Gountouna, V. E., McGonigle, D. J., \& Logie, R. H. (2010). Loss of imagery phenomenology with intact visuo-spatial task performance: A case of 'blind imagination'. Neuropsychologia, 48(1), 145-155. https://doi.org/10.1016/j.neuropsychologia.2009. 08.024.

Zeman, A. Z. J., Dewar, M., \& Della Sala, S. (2015). Lives without imagery-Congenital Aphantasia. Cortex. https://doi.org/10.1016/j.cortex.2015.05.019.

Zeman, A. Z. J., Dewar, M., \& Della Sala, S. (2016). Reflections on aphantasia. Cortex, 74, 336-337. https://doi.org/10.1016/j.cortex.2015.08.015.

Zeman, A. Z. J., Mackiasack, M., \& Onians, J. (2018). The Eye's mind-Visual imagination, neuroscience and the humanities. Cortex., 105, 1-3. https://doi.org/10.1016/j.cortex.2018.06.012.

Zimmer, C. (2010). The brain. Discover, 28-29.

Publisher's Note Springer Nature remains neutral with regard to jurisdictional claims in published maps and institutional affiliations. 